\title{
Should We Be Using Just 'Typical' Weather Data in Building Performance Simulation?
}

\author{
Drury B. Crawley ${ }^{1}$, Linda K. Lawrie ${ }^{2}$ \\ ${ }^{1}$ Bentley Systems, Inc., Washington, DC, USA \\ ${ }^{2}$ DHL Consulting LLC, Pagosa Springs, CO, USA
}

\begin{abstract}
Over the past 40 years, organizations worldwide have created weather data sets specifically for use in building energy simulation, usually called typical or reference years. Crawley (1998) showed how a variety of typical data sets compare in terms of impacts on building energy. This study found that TRY-type files (single years) do not represent the period of record well and recommends TMY or other weather data created using similar procedures, such as European test reference years.

Several other studies have concluded that TMY are good enough to represent typical building operation. Yet we need weather that represents a reasonable range of climate conditions that buildings experience. A 2015 study proposed development of eXtreme Meteorological Year (XMY) weather files to represent the range of climate conditions that buildings may experience. An XMY starts with the same period of record as the TMY, but the methodology purposely selects more extreme months.

This paper proposes a new regime for climatic data representation in buildings - an XMY or eXtreme Meteorological Year. We demonstrate how several sets of international typical meteorological data sets compare to the actual period of record that they represent. Then using prototype buildings, we show that the climatic response of the building would be better served by a range of building climatic data, investigating high and low cases of temperature, humidity, solar radiation and wind conditions.
\end{abstract}

\section{Introduction}

Over the past 40 years, organizations throughout the world have created weather data sets specifically designed for use in building energy simulations, usually called typical or reference years.

One of the earliest weather data sets for building performance simulation is the Test Reference Year (TRY) (NCDC 1976) for 60 locations in the United States. The TRY contain hourly dry-bulb temperature, wet-bulb temperature, dew point, wind direction and speed, barometric pressure, relative humidity, cloud cover and type, and a placeholder for solar radiation; however, no measured or calculated solar data are included. When used for building energy simulations, the simulation program must calculate the solar radiation based on the cloud cover and cloud type information available in the TRY. The TRY are an actual historic year of weather, selected using a process where years in the period of record ( 1948-1975) which had months with extremely high or low mean temperatures were progressively eliminated until only one year remained. This results in a mild year that usually excludes extreme conditions. To deal with the limitations of the TRY, particularly the lack of solar data, the National Climatic Data Center (NCDC) worked together with Sandia National Laboratory (SNL) to create a new data set, Typical Meteorological Year (TMY). TMY include, in addition to the data contained in TRY, total horizontal and direct normal solar radiation data for 234 U.S. locations (NCDC 1981). The method used is like that used for the TRY, but the TMY method selects individual months rather than entire years. The resulting TMY data files each contain months from many different years.

Crawley (1998) demonstrated how European TRY, TMY2, CTZ, CTZ2, CWEC, WYEC, WYEC2, and IWEC data sets compare in terms of impacts on building energy performance. Crawley discourages the use of the TRY-type method while recommending the TMY or other data created using similar procedures, such as ISO Standard 1592704:2005 (ISO 2005). Crawley and Barnaby (2019) provide details on the developments of typical reference and meteorological years as wells as other climatic data over the past fifty years.

\section{Methodology}

In a 2015 study (Crawley and Lawrie 2015), we selected an initial set of variables including dry-bulb temperature, dew-point temperature, solar insolation, precipitation, relative humidity, and wind speed. Then we evaluated these variables against the period of record: monthly extreme (average and daily), seasonal extreme, and single year.

Using these potential XMYs, five reference buildings (Deru et al 2011) were simulated using EnergyPlus (Crawley et al 2001) in six locations -- this showed that the monthly XMYs resulted in energy use outside that shown by the actual period of record (see Figure 1). Lines indicate the XMY cases versus the individual years. In this and other locations, the XMYs developed using this method either did not bracket the range of 
140

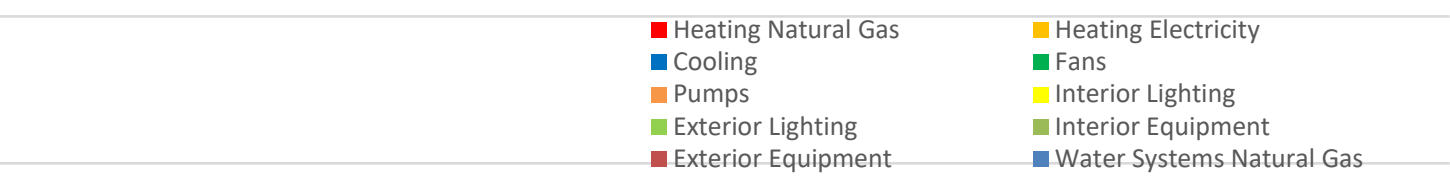

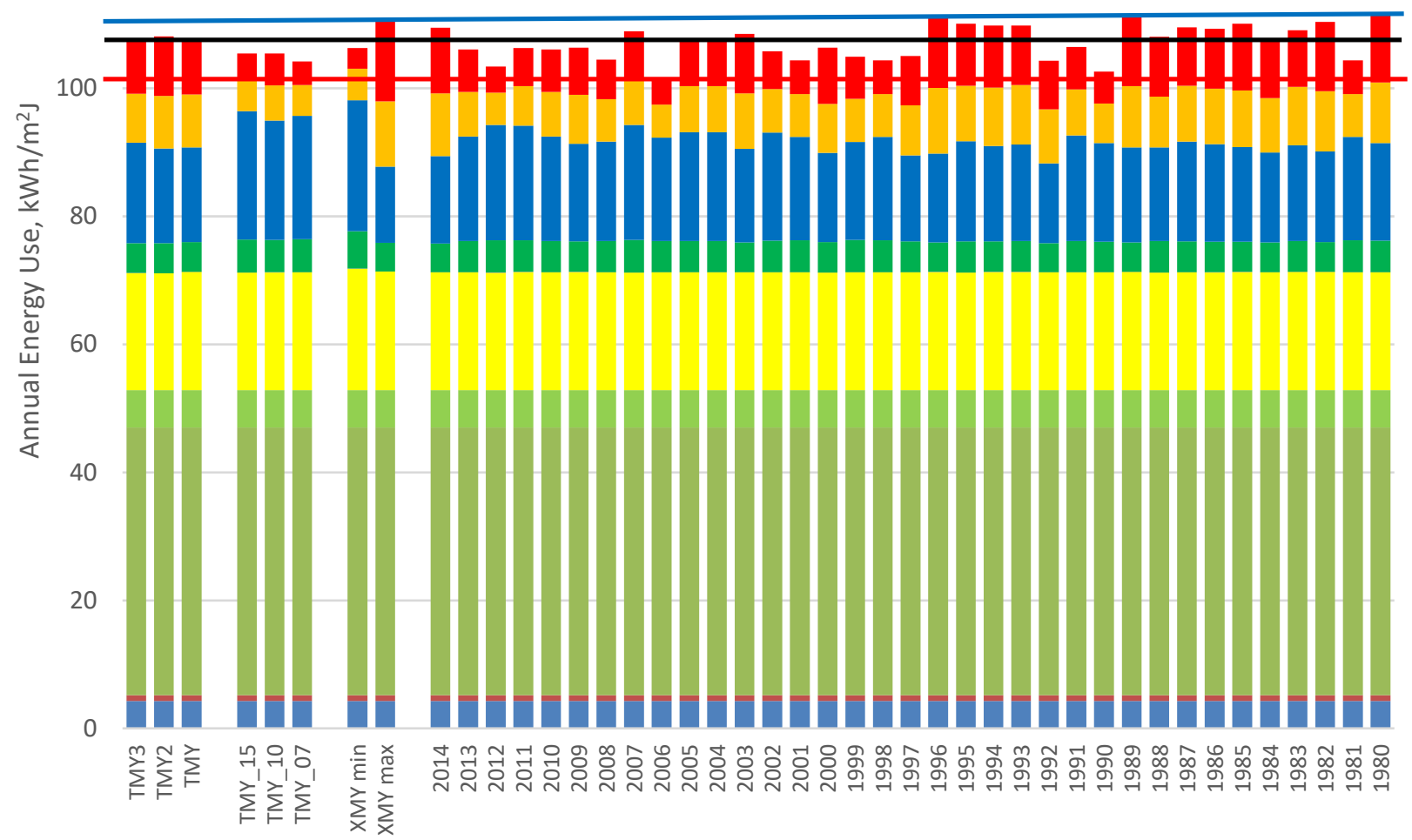

Figure 1. Medium Office Building using Washington Dulles AP Weather Based on Selecting Extreme Months for XMYs (Crawley and Lawrie 2015)

the results for individual years or were far beyond what was see in the individual years. The monthly XMYs with the greatest difference in energy use between min and max were dry-bulb temperature, dew-point temperature, and precipitation. Minimum and maximum relative humidity and wind speed showed very little impact on energy performance while solar insolation shows less variation. This also showed clearly that weather influence focused on heating, cooling, fans, and pumps.

\section{New XMY Months Selection Methods Tested}

After finding that selecting extreme months to construct XMYs did not properly bracket the range of individual years, we decided to look at other ways of automatically determining appropriate XMY configurations. Concentrating on extreme temperatures in the historical data, we have used several methods to create potential XMY years, implementing four approaches: descending Finkelstein-Schafer statistic (FS-Stat) as used in creating TMYs; selecting months with high/low 6-month seasonal average temperatures; selecting months based on high/low 3-month seasonable weights; and selecting months based on high/low 3-month seasonal weights based on the F-S Stat. Each had several variants as described below. By going from selecting individual months to either 3- or 6-month seasons, we believed that an XMY using these approaches would better represent the range of years.

At the same time, we created TMYs for five locations selected to cover a range of climate conditions: Washington Dulles AP, Virginia, USA; London Heathrow AP, UK; Denver AP, Colorado, USA; Montreal Trudeau AP, Quebec, Canada; and Changi AP, Singapore. We used the same weights used to create the IWEC (ASHRAE 2001): dry bulb mean: 30\%, daily total solar: $40 \%$, then dry bulb $\max / \min : 5 \%$, wind speed max/min: $5 \%$ and dew point $\mathrm{max} / \mathrm{min} 2.5 \%$. As described by Crawley and Lawrie (2015), these were the variables that best describes the inter-annual variation. For these five locations, we created two TMYs: one which covered the entire period of period (Dulles 55 years, Heathrow 55 years, Denver 23 years, Montreal 44 years, Singapore 39 years) and a second TMY, which was derived from the last 15 years of data. Then for each building type, we simulated the entire span of available years along with the TMYs using EnergyPlus.

In more detail, here are the approaches used to create XMYs (both full and recent files were created):

- Based on the FS-Stat composite index (same used in creating TMYs) with IWEC weights but selecting months based on composite indices descending from 
high to low. Normal TMYs use the FS-Stat index but sort from low to high values.

- Based on the FS-Stat composite index with dry bulb and solar each weighted $40 \%$ but selecting months based on composite indices descending from high to low values.

- Select seasons based on Seasonal Average Temperatures (Winter Min, Summer Max) (6 months each)

- Select seasons based on Reverse Seasonal Average Temperatures (Summer Min, Winter Max) (6 months each)

- Based on FS-Stat composite index for Seasonal Weightings (Winter min, Summer Max, IWEC other) (3-month seasons), select seasons from descending high to low values.

- Based on FS-Stat composite index for Reverse Seasonal Weightings (Winter max, Summer Min, IWEC other) (3-month seasons), select seasons from descending high to low values.

This yields two different approaches to determining months that are at the high and low end of what is possible in the period of record: FS-Stat and seasonal averages. Each of these variants was created for five locations and EnergyPlus simulations run for the building prototypes. The following discussion shows results for the medium office prototype (Deru et al 2011, $4,982 \mathrm{~m}^{2}, 3$ floors, 18 zones, with thermal characteristics based on Standard 90.1-2013 (ASHRAE 2013) in the five locations.

\section{Results and Discussion}

Figure 2 shows all the results of the various candidate XMY method cases described above using data for Washington Dulles AP. This includes individual years from 1963 through 2017 as well as TMYs for the last 15 years and all 55 years of data (the last two bars). The two lines are the years with the highest and lowest energy, 1977 and 2006, respectively. If the XMY works well, it should be close to those values. The Seasonal Average and Reverse Seasonal Average selection month (6month seasons) produce energy results that capture the range of energy use (and beyond) of all the years in the period of record. While the XMY variants using the FSStat declining indices produce results closer to the top energy using individual years, they do not capture the lower energy use. Figure 3 shows similar data for Washington but omits the individual years to make it easier to discern trends. (Note that Figures 2-9 have heating, then cooling, etc.; the reverse of Figure 1.) Heating is a prime driver in Washington, DC even though summers are quite hot - it can vary by $\pm 50 \%$ between years (see 1989 and 1990, for example and the high and low years, 1997 and 2006, respectively). Heating is the prime variant for all locations except Singapore. On the other hand, cooling is reasonably consistent year to year in Washington. Thus, methods that balance heating and cooling, such as seasonal average will yield better matches compared to methods that select months based on weighted F-S statistics.

Figures 4 and 5 shows similar results for London Heathrow AP. Again, the Seasonal Average XMYs

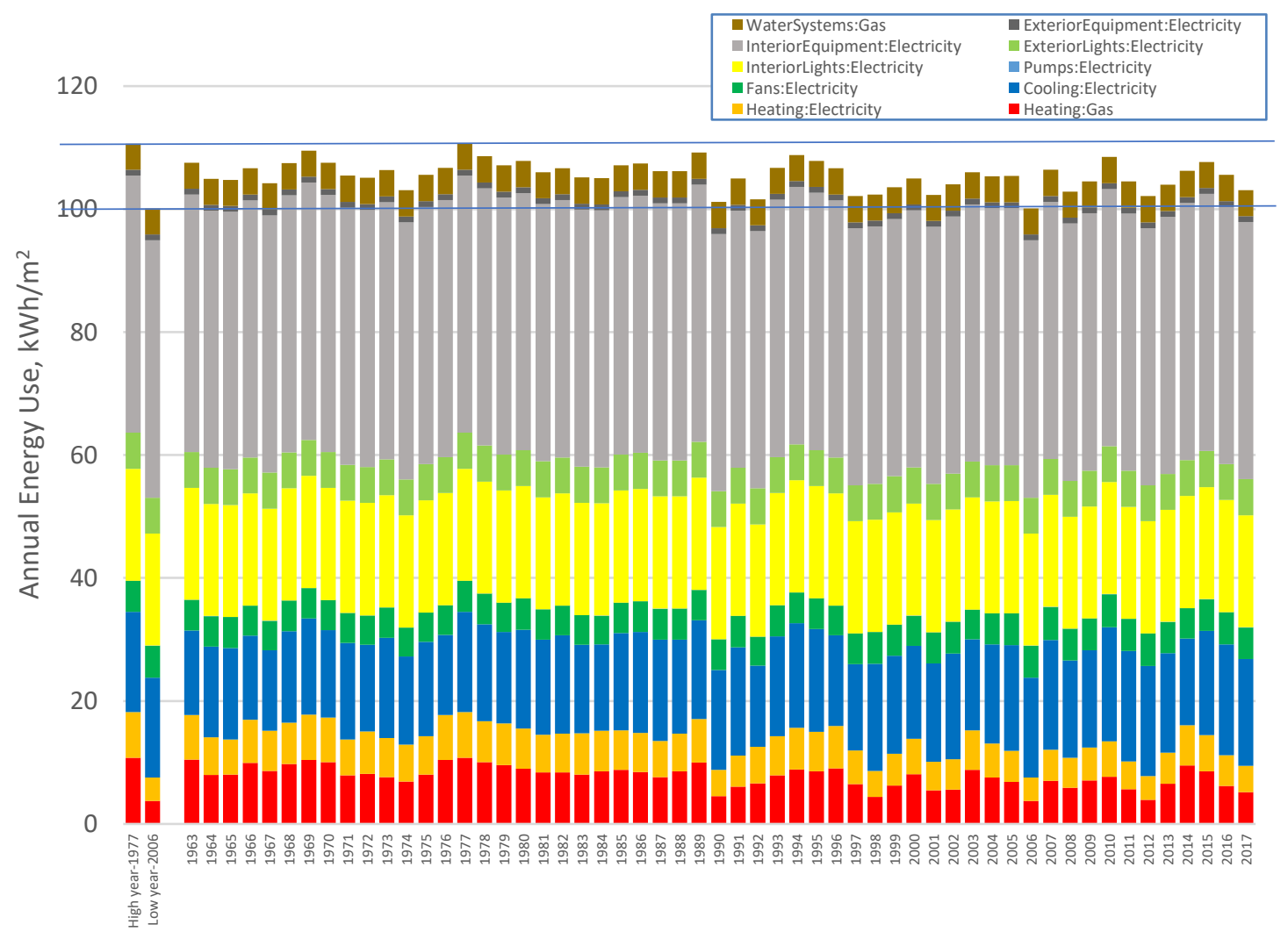

Figure 2. Medium Office Building at Washington Dulles AP with MYs and High and Low Energy Years 


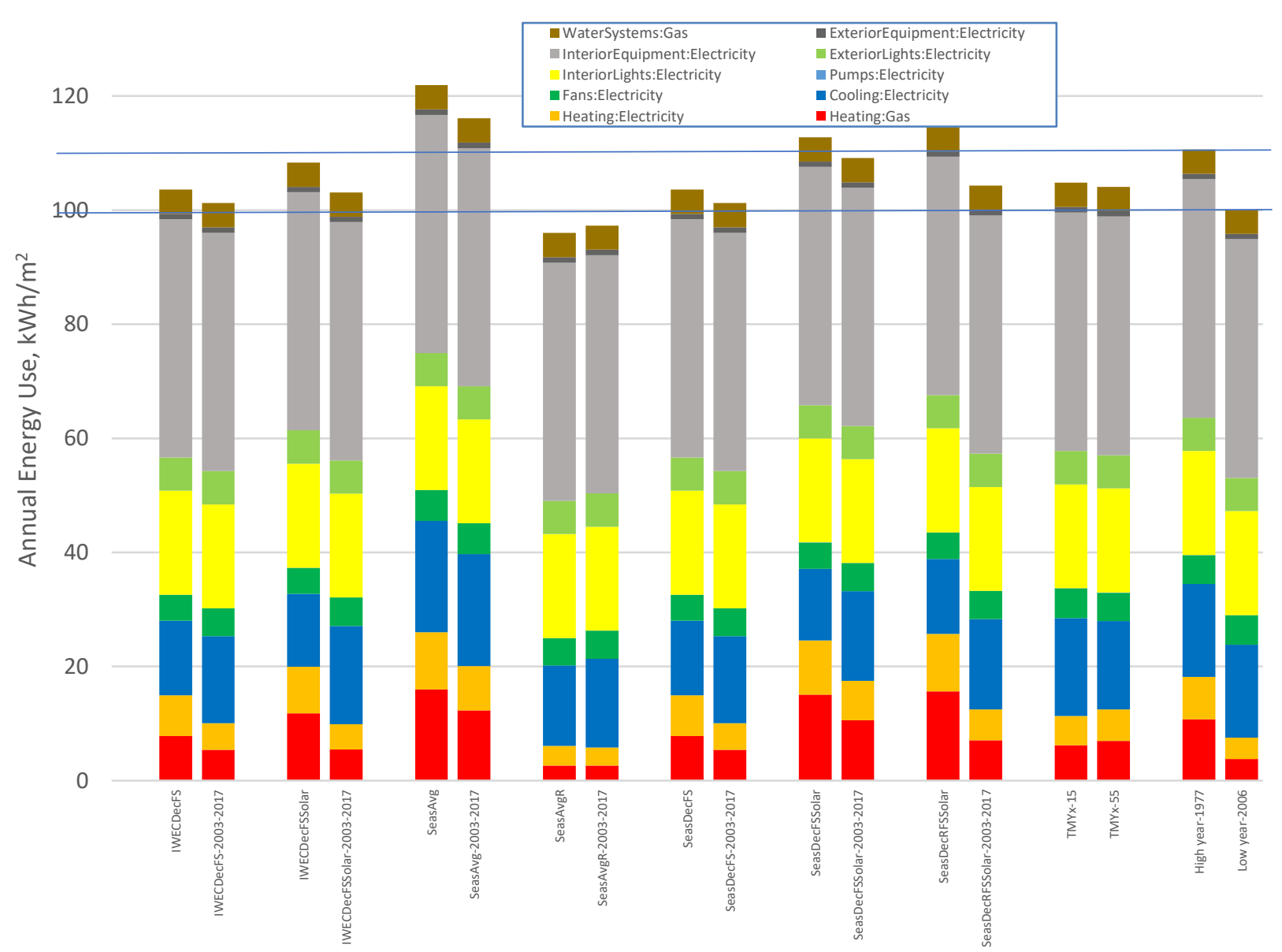

Figure 3. Medium Office Building at Washington Dulles AP with XMYs Selected from Seasonal Data

produce better results than the FS-stat cases and none of the FS-stat cases capture the lower energy use cases well. Compared to Washington, DC, London has much higher heating, which is more consistent, year to year. However, cooling varies by a factor of 4 or more and is usually only one-third of heating. Thus, again selecting XMYs using seasonal temperatures results in XMYs that are closer to the range of individual years over the period of record.

Figures 6-9 show results for Denver, Singapore, and Montreal, similar to Washington and London. Figure 6 shows results for Denver AP and Figure 7 shows results for Singapore Changi AP (XMYs only for both Denver and Singapore as the inter-annual variation is small); Figures 8 and 9 for Montreal AP; and. And with Heathrow and Dulles, the Seasonal Average variants capture the high and low end of the energy use range for all the period of record, except for Singapore. Denver, like Washington has significant heating and cooling and the heating varies by $70 \%$ between high and low years but cooling variation is only $5 \%$. For Montreal, heating is five times that of cooling and varies by more than $50 \%$ from high to low years. Singapore, heating is essentially zero and the variation in cooling is only $17 \%$ from high to low year. Like Heathrow, the FS-stat variants do not capture the lower end well for Denver, Montreal or Changi. Singapore is the only location of the five where the Seasonal Average variants do not capture the low range of energy use. We believe this is due to the small variation in cooling across the year and almost complete lack of heating. Other variables such as precipitation may work better there. In all cases, it is encouraging that the TMY are near the mean of the results for all the years.

What does this mean for the methodology proposed here for determining an XMY for a location? We believe that using Seasonal Average to determine the best combination of XMY has the greatest promise. However, tropical climates such as Singapore may require another variable (dry bulb temperature was used to determine seasons in this study). We believe that variations in weighting (or eliminating weights) may solve this issue and are continuing to study it. By going from the IWEC weights to the higher weights on dry bulb and solar, the range covered by the XMYs was significantly increased. Work under way is investigating whether increasing or decreasing those weights (dry bulb and solar) further will consistently better match the longterm results.

\section{Summary and Conclusions}

This paper proposes a new regime for climatic data representation in buildings - an XMY or eXtreme 


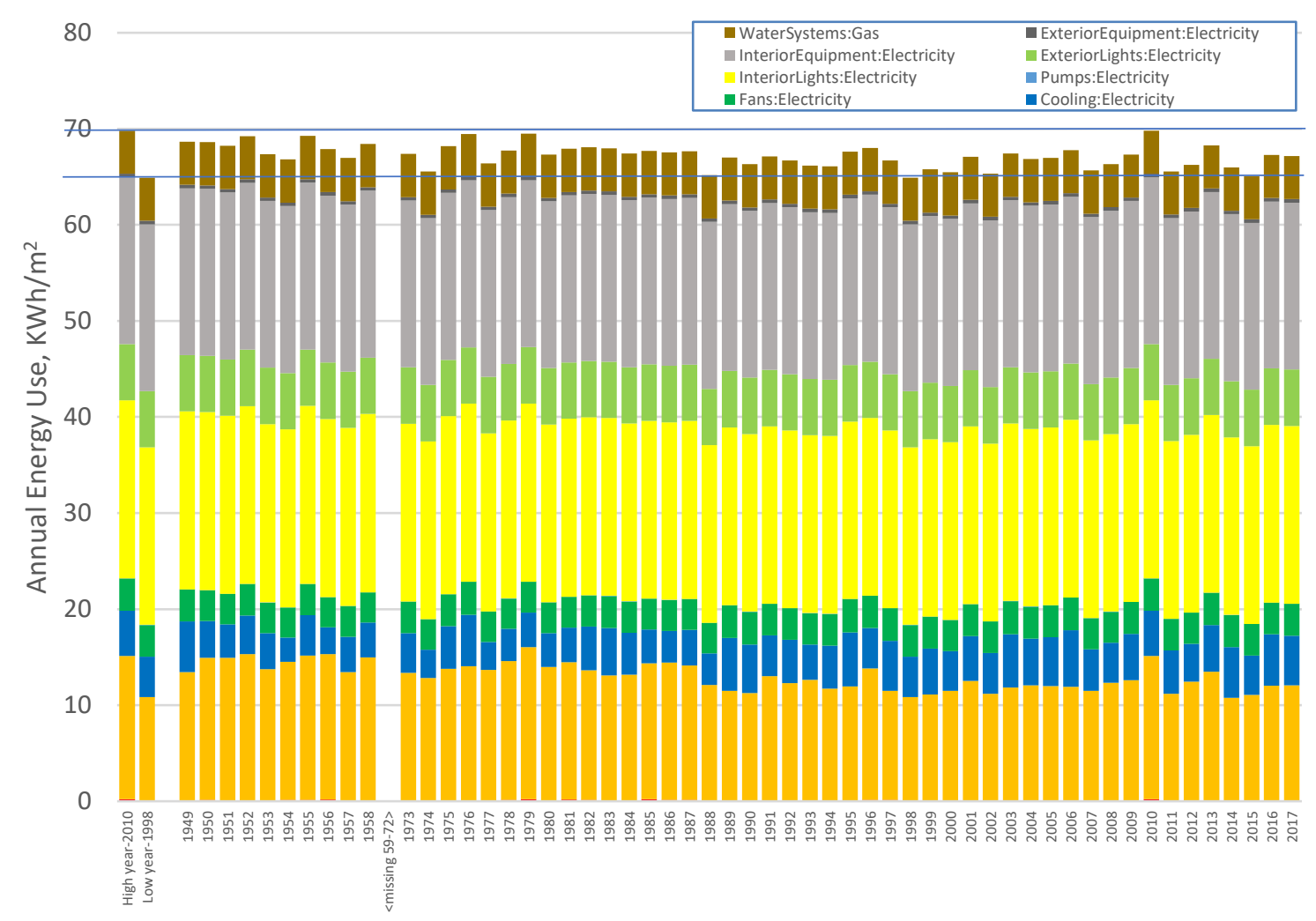

Figure 4. Medium Office Building at London Heathrow AP with MYs and High and Low Energy Years

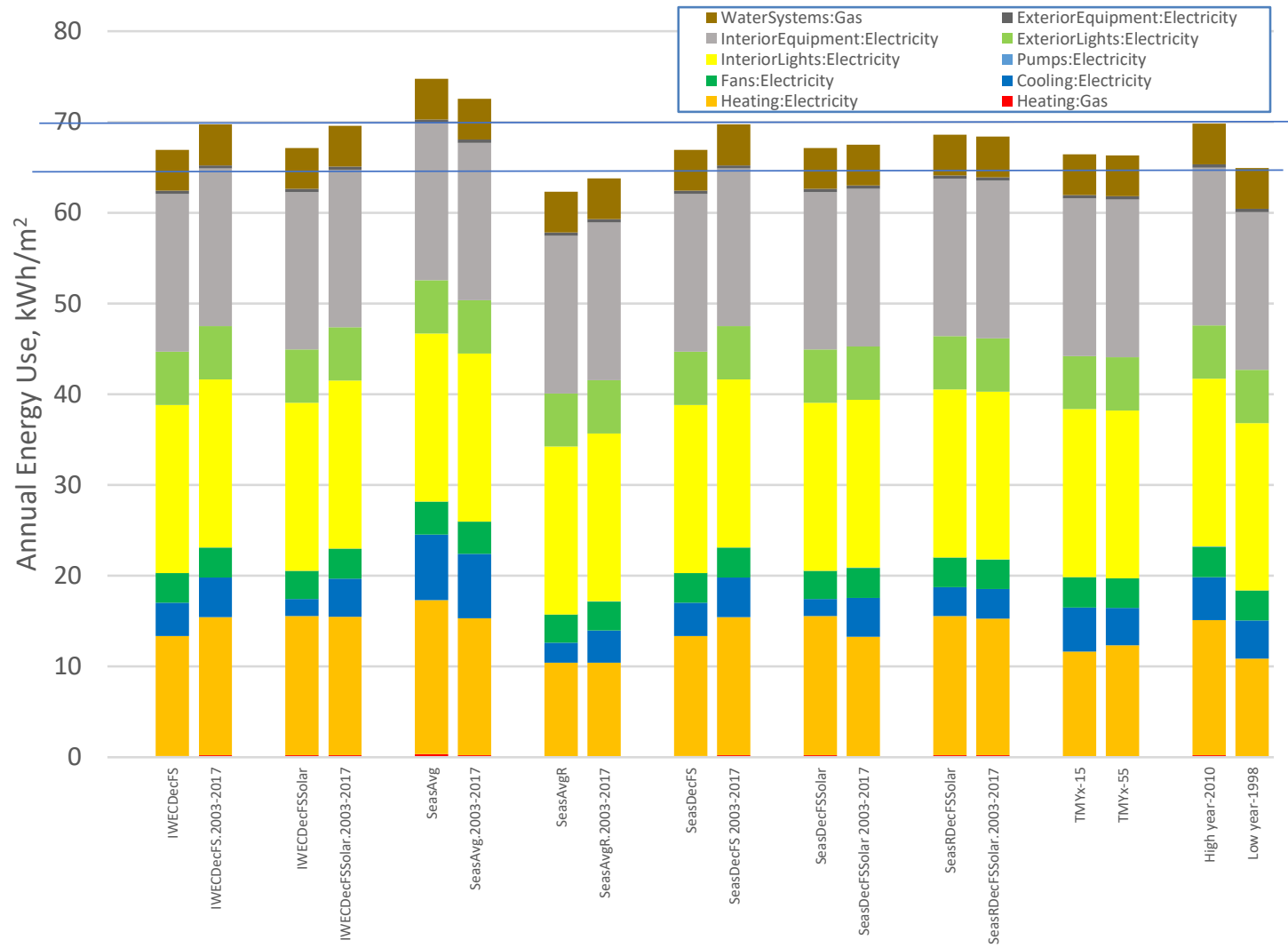

Figure 5. Medium Office Building at London Heathrow AP with XMYs Selected from Seasonal Data 


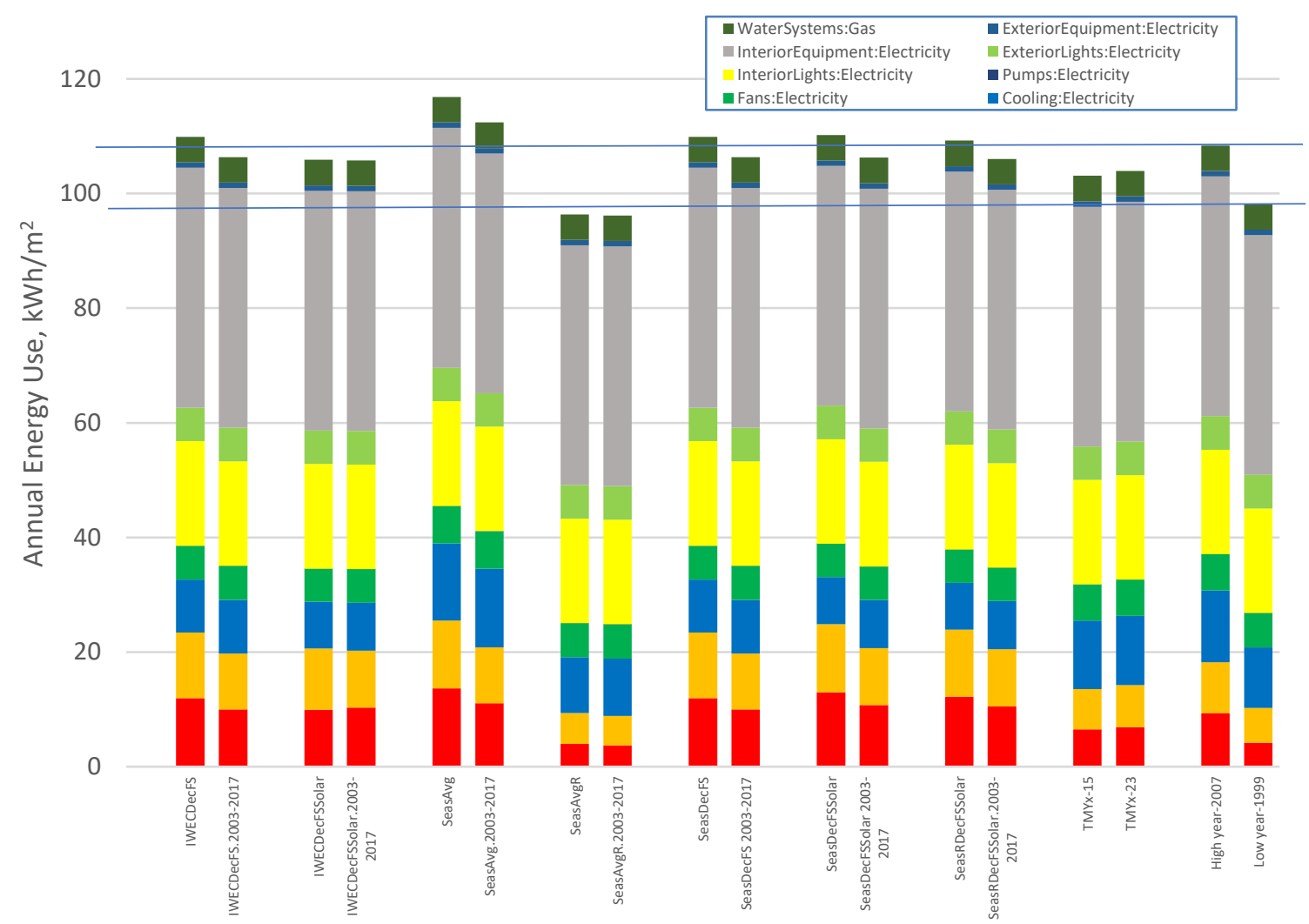

Figure 6. Medium Office Building at Denver AP with XMYs Selected from Seasonal Data

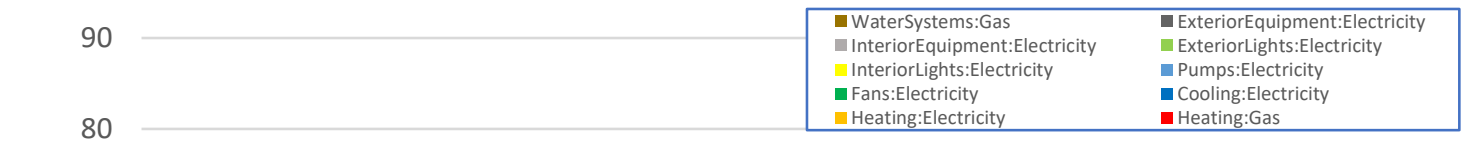

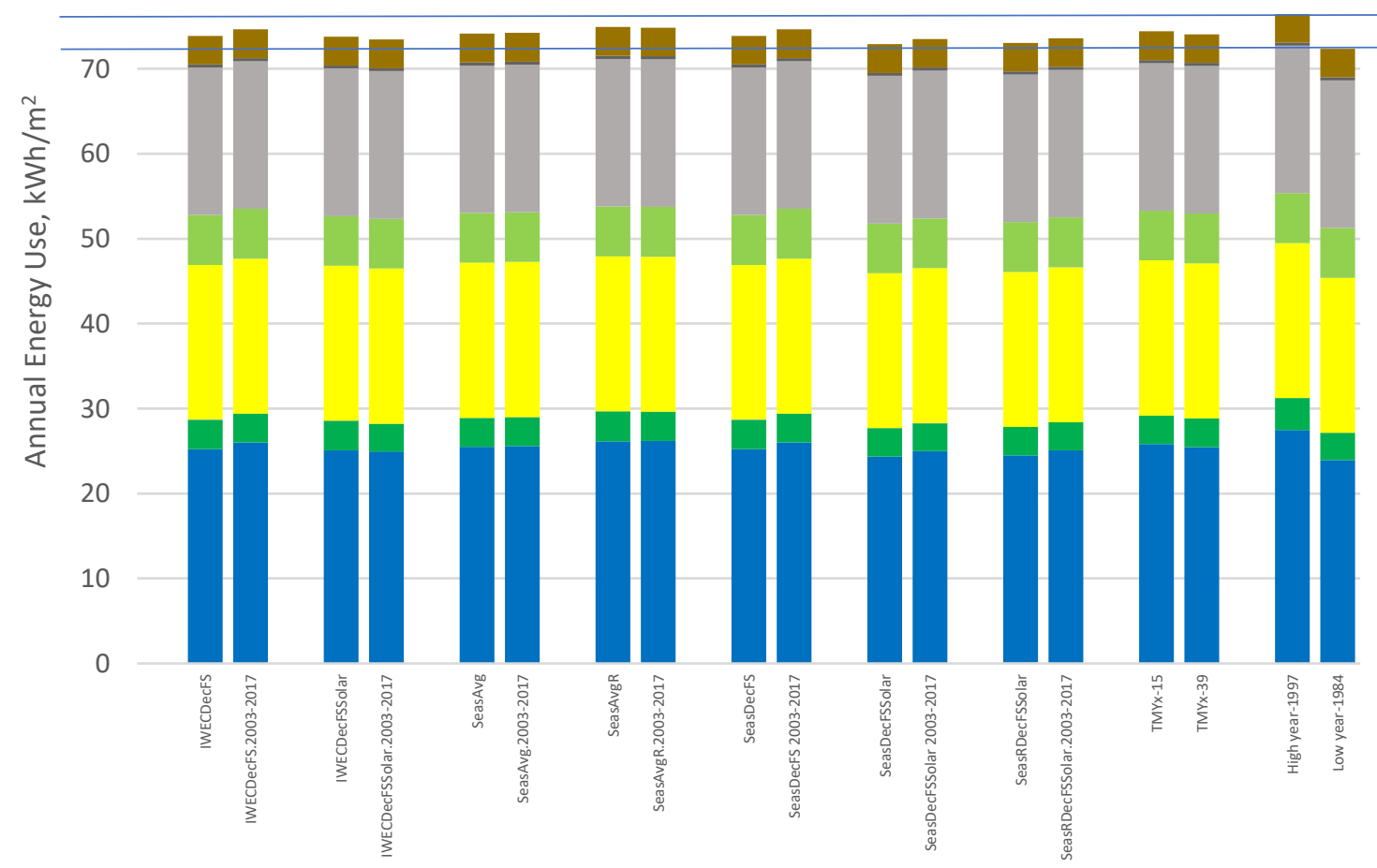

Figure 7. Medium Office Building at Singapore Changi AP with XMYs Selected from Seasonal Data 


\begin{tabular}{|c|c|c|c|}
\hline 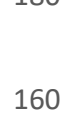 & & $\begin{array}{l}\text { WaterSystems:Gas } \\
\text { InteriorEquipment:Electricity } \\
\text { InteriorLights:Electricity } \\
\text { Fans:Electricity } \\
\text { Heating:Electricity }\end{array}$ & $\begin{array}{l}\text { - ExteriorEquipment:Electricity } \\
\text { ExteriorLights:Electricity } \\
\text { Pumps:Electricity } \\
\text { - Cooling:Electricity } \\
\text { - Heating:Gas }\end{array}$ \\
\hline
\end{tabular}

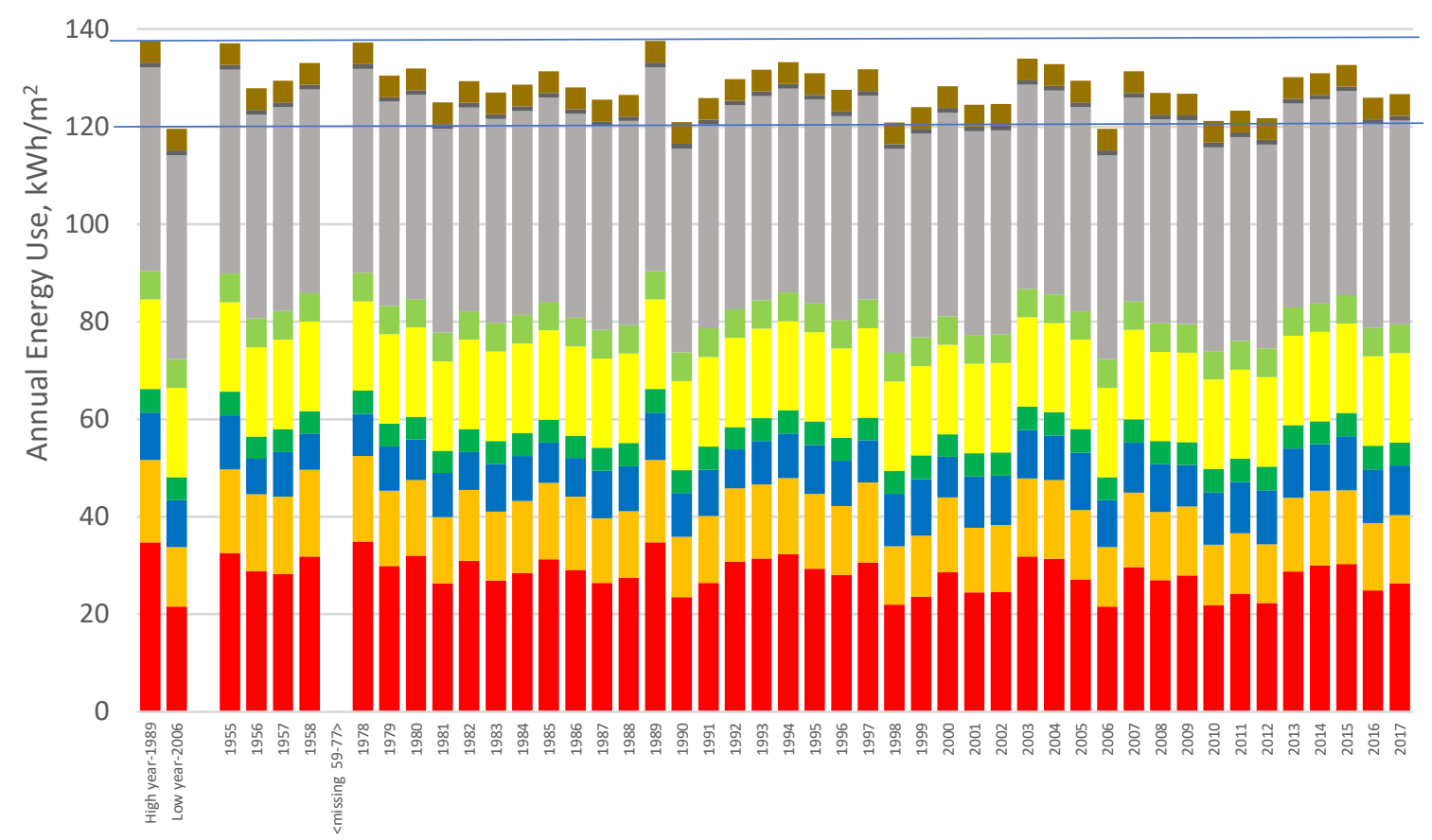

Figure 8. Medium Office Building at Montreal Trudeau AP with MYs and High and Low Energy Years

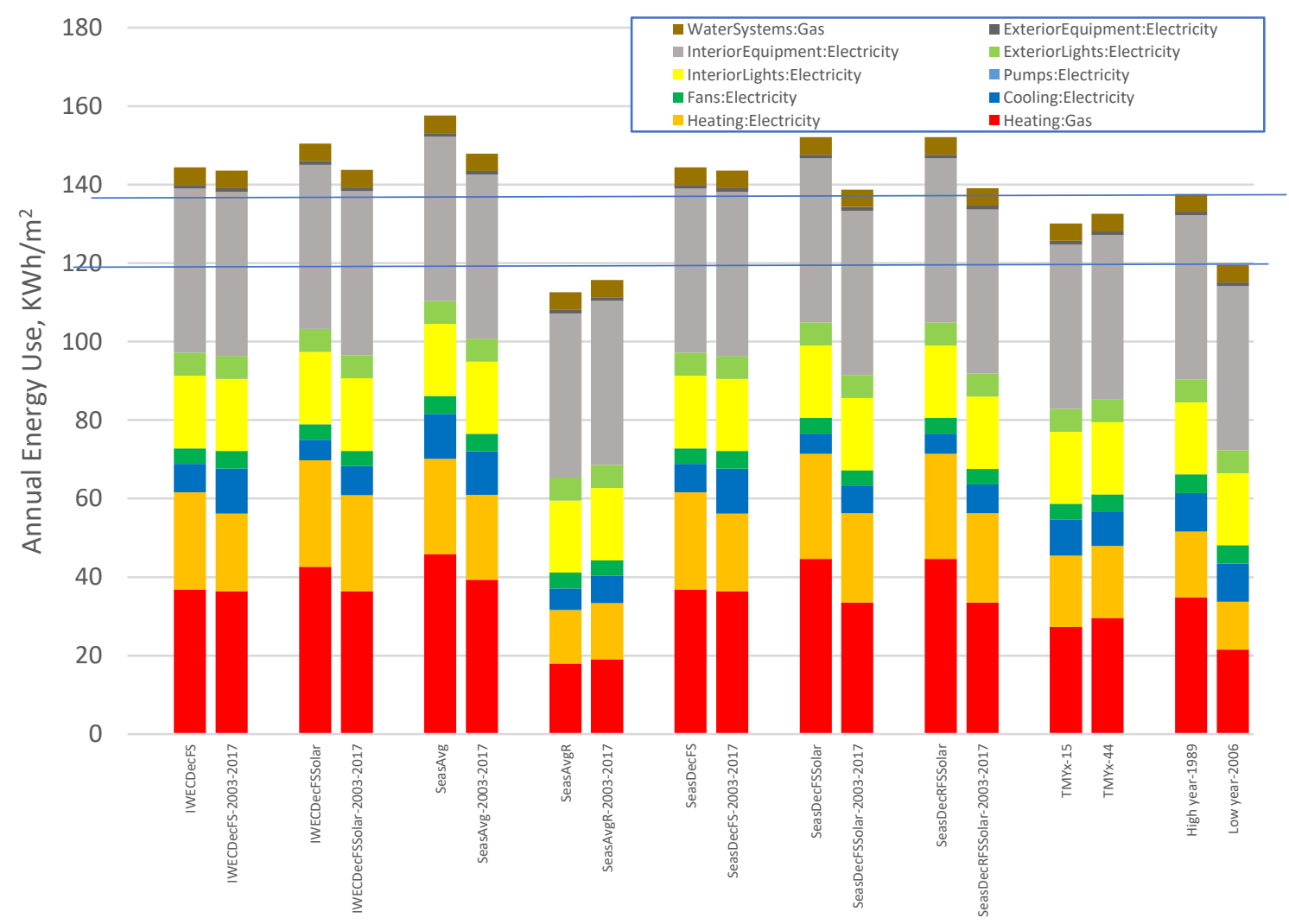

Figure 9. Medium Office Building at Montreal Trudeau AP with XMYs Selected from Seasonal Data 
Meteorological Year-building on a paper that called for a common format for building simulation representation.

We demonstrate how several sets of international typical meteorological data sets compare to the actual period of record that they represent. Then using prototype buildings, we show that the climatic response of the building would be better served by XMYs that cover the range of building climatic data including high and low cases of temperature, humidity, solar radiation and wind conditions. We recommend the use of higher weights on dry bulb and solar radiation than in the traditional TMY methods using Seasonal Averages to select the months to comprise XMYs that capture the potential range of energy use of the individual years. These results also demonstrate that the TMY method consistently produces weather files that are close to the mean or average of the years from which they are derived. Based on the results of this study, we believe that building simulations should include consideration of more than a single typical year of weather data, such as the XMYs presented here. However, we are still working on the method for selecting XMYs that will work across all climates.

\section{References}

ASHRAE. 2013. ANSI/ASHRAE/IES Standard 90.12013, "Energy Efficient Design of New Buildings except Low-Rise Residential Buildings.” Atlanta: ASHRAE.

ASHRAE. 2001. International Weather for Energy Calculations (IWEC Weather Files) User's Manual and CD. Atlanta, GA: ASHRAE, Inc.

Crawley, Drury B. and Charles S. Barnaby. 2019. "Chapter 6, Weather and Climate in Building Performance Simulation." In Building Performance Simulation for Design and Operation, $2^{\text {nd }}$ edition, edited by Jan L. M. Hensen and Roberto Lamberts, pp. 191-220. New York, U.S.A.: Taylor \& Francis Group.

Crawley, Drury B. and Linda K. Lawrie. 2015. "Rethinking the TMY: Is the 'Typical' Meteorological Year Best for Building Performance Simulation?" in Proceedings of BS 2015: 14th Conference of International Building Performance Simulation Association, pp. 2655-2662, 7-9 December 2015, Hyderabad, India.
Crawley, Drury B. 2008. "Estimating the impacts of climate change and urbanization on building performance," in Journal of Building Performance Simulation, Volume 1, Issue 2, pp 91-115.

Crawley, Drury B., Linda K. Lawrie, Frederick C. Winkelmann, W.F. Buhl, Y. Joe Huang, Curtis O. Pedersen, Richard K. Strand, Richard J. Liesen, Daniel E. Fisher, Michael J. Witte, Jason Glazer, 2001. "EnergyPlus: Creating a New-Generation Building Energy Simulation Program," Energy and Buildings, pp. 319-331, Vol. 33, No. 4 (April 2001).

Crawley, Drury B., Jon W. Hand, and Linda K. Lawrie. 1999. "Improving the Weather Information Available to Simulation Programs," in Proceedings of Building Simulation '99, Volume II, pp. 529-536, Kyoto, Japan, September 1999. IBPSA.

Crawley, Drury B. 1998. "Which Weather Data Should You Use for Energy Simulations of Commercial Buildings?" in ASHRAE Transactions, pp. 498-515, Vol. 104, Pt. 2. Atlanta: ASHRAE.

Deru, Michael, Kristin Field, Daniel Studer, Kyle Benne, Brent Griffith, Paul Torcellini, Bing Liu, Mark Halverson, Dave Winiarski, Michael Rosenberg, Mehry Yazdanian, Joe Huang, Drury Crawley. 2011. U.S. Department of Energy Commercial Reference Building Models of the National Building Stock, Technical Report NREL/TP-5500-46861, February 2011. Golden, Colorado: NREL.

ISO. 2005. ISO Standard 15927-4:2005, Hygrothermal Performance of Buildings - Calculation and Presentation of Climatic Data - Part 4: Hourly Data for Assessing the Annual Energy Use for Heating and Cooling. International Standards Organization. Geneva, Switzerland: ISO. www.iso.org/standard/41371.html.

NCDC. 1976. Test Reference Year (TRY), Tape Reference Manual, TD-9706, September 1976. Asheville. North Carolina: National Climatic Data Center, U.S. Department of Commerce.

NCDC. 1981. Typical Meteorological Year User's Manual, TD-9734, Hourly Solar Radiation-Surface Meteorological Observations, May 1981. Asheville, North Carolina: National Climatic Data Center, U.S. Department of Commerce. 